\title{
O TERRÁRIO NO ENSINO DA ECOLOGIA: UMA PROPOSTA PARA A FORMAÇÃO INICIAL DE PROFESSORES
}

\author{
Joberth Rainner Baliza de Paula (IC) ${ }^{1}$,
}

Mateus Paulo da Silva (IC) ${ }^{2}$,

\section{Antonio Fernandes Nascimento Junior (PQ) ${ }^{3}$}

Resumo: Os problemas decorrentes da degradação ambiental têm sido frequentes no cenário mundial. O meio ambiente e as implicações ecológicas derivadas de ações humanas fazem parte de todas as orientações e parâmetros curriculares para o ensino básico brasileiro. Visando trabalhar conceitos relacionados ao ensino de ecologia com estudantes do ensino básico foi visto que o terrário pode ser um recurso que permite construir conceitos relacionados aos ecossistemas terrestres. Tendo em vista que este recurso se torna relevante por proporcionar uma realidade palpável de forma esquematizada de um modelo da biosfera. Nesse sentido, foi proposto um minicurso com foco na formação de professores, utilizando o terrário como tema gerador para EA. Este aconteceu durante a $11^{\text {a }}$ Semana Nacional de Museus, no Museu de História Natural da Universidade Federal de Lavras. Os resultados indicaram que a utilização do terrário na formação de professores, se mostrou uma ferramenta com grande potencial como modelo

\footnotetext{
${ }^{1}$ Acadêmico do Curso de Licenciatura em Ciências Biológicas, bolsista de Iniciação Científica FAPEMIG e participante do Laboratório de Educação Científica e Ambiental irb.depaula@gmail.com

${ }^{2}$ Acadêmico do Curso de Licenciatura em Ciências Biológicas, bolsista do Programa Institucional de Bolsas Iniciação à Docência da UFLA e participante do Laboratório de Educação Científica e Ambiental mateussilva31@gmail.com

${ }^{3}$ Prof. adjunto, do Departamento de Biologia da UFLA e líder do Laboratório de Educação Científica e Ambiental . Lavras-MG. toni nascimento@yahoo.com.br
} 
para o processo ensino-aprendizagem em ecologia por favorecer a visualização de seus aspectos conceituais e sociais. Espera-se com este tipo de trabalho, ajudar a desenvolver um pensamento crítico no processo de construção do conhecimento, relacionando-o com conteúdos presentes nas propostas curriculares e no cotidiano dos estudantes, além de atuar como uma prática interdisciplinar.

Palavras-Chave: Educação ecológica. Terrário. Formação de professores.

\section{INTRODUÇÃO}

A preocupação com a degradação ambiental tem sido foco de diversos trabalhos que visam à reconstrução de conceitos e sensibilização da sociedade. Segundo Veronez et. al (2009) as tragédias em virtude dos eventos climáticos tem sido cada vez mais noticiadas. O aquecimento global, surgimento de doenças e extinção de animais faz com que as pessoas repensem suas atitudes perante a natureza.

O meio ambiente e as implicações ecológicas derivadas de ações humanas fazem parte de todas as orientações e parâmetros curriculares para o ensino básico brasileiro. (BRASIL, 2006, BOTELHO, 2008). No entanto, segundo Philippi Jr. \& Pelicioni, (2005) a Educação Ambiental (EA) implica na interdisciplinaridade e em experiências educativas que provocam a percepção integrada do meio ambiente, o que corrobora com Parâmetros Curriculares Nacionais ao destacar a necessidade de possibilitar ao aluno uma ação mais racional e capaz de atender às necessidades sociais.

A ecologia política compreende uma área de estudo de diferentes agentes sociais com poderes desiguais (LOUREIRO \& LAYRARGUES, 2013), busca compreender o funcionamento de um sistema em que a sociedade se insere, visando intervenções políticas que vão além das relações de reprodução de um modo específico de produção e propriedade dos bens naturais, no qual o sistema econômico se caracteriza por uma qualidade de vida de um pequeno grupo comparado ao prejuízo que uma grande maioria que é submetida em relação ao uso abusivo da natureza. 
Tendo em vista que a natureza em toda sua extensão não se apresenta exclusivamente como fonte de recursos, mas antes de tudo o alicerce para a existência humana, o pensamento ecologicamente político vai ao encontro da educação ambiental crítica que se resume segundo Loureiro (2013) em três situações pedagógicas, sendo estas: (1) análise da situação real, com o intuito de compreender as bases que possibilitam questionar as situações sócio-históricas que culminaram no modelo de desigualdade e conflitos ambientais; (2) trabalho da autonomia e liberdade dos agentes envolvidos nas relações de desapropriação, opressão e dominação de uma realidade capitalista e por fim (3) inserção da transformação do padrão societário dominante, onde é visível a intensa degradação ambiental e condição humana.

Diante disso, as Orientações Educacionais Complementares aos Parâmetros Curriculares Nacionais, Brasil (2006, p.31) sugerem que é preciso possibilitar ao aluno um comportamento crítico e criativo diante do processo de ensino aprendizagem, assim, atividades de experimentação com o uso de modelos didáticos podem se tornar uma ferramenta que proporciona segundo Melo (2010) uma estratégia motivadora, pois possibilita ao aluno maior interação e participação no processo de construção do conhecimento, permitindo maior contato entre teoria e prática.

É importante essa interação entre teoria e prática, uma vez que segundo Gasparin e Petenucci (2008), o educador conhecendo a teoria que sustenta a sua prática, pode suscitar transformações na conscientização dos educandos e demais colegas, chegando até aos condicionantes sociais, tornando o processo ensino-aprendizagem em algo realmente significativo, em prol de uma educação transformadora, que supere os déficits educacionais e sociais atuais.

Visando trabalhar conceitos relacionados à Educação Ecológica com estudantes do ensino básico foi visto que o terrário pode ser um recurso de experimentação que permite construir conceitos, tendo em vista que este, segundo Rosa (2009), é apresentado como um modelo reduzido de ecossistemas terrestres.

A construção do terrário se apresenta como um recurso didático relevante por proporcionar ao aluno uma realidade palpável de forma esquematizada, tornando-a mais inteligível possibilitando um pensamento tridimensional (KRASILCHICK, 2004, p.62) de um modelo da biosfera e das necessidades básicas dos seres vivos. 
De acordo com o PCN:

Um vaso de planta, um aquário ou um terrário feito em uma garrafa podem permitir o desenvolvimento de múltiplos conteúdos sem grandes gastos de dinheiro ou de tempo. Mais do que contornar uma situação desfavorável, tais práticas permitem ao aluno um novo olhar sobre o corriqueiro. (BRASIL, 2006, p32)

O terrário é uma pequena representação de um ambiente em que não há a intervenção direta do ser humano e onde as variáveis globais podem ser controladas (Veronez et. al, 2009). Não necessita de muitos recursos para ser planejado e construído, para isso, depende da criatividade do professor e dos materiais disponíveis. Através dele, uma gama de conteúdos podem ser explorados e, segundo Veronez et.al. (2009) a partir das observações por parte dos estudantes é possível verificar os conhecimentos e desenvolver outras atividades que possam complementar e suplementar sua formação.

Devido a sua importância e afinidade com o tema Educação ecológica e ambiental, o terrário pode ser uma importante ferramenta pedagógica no ensino da mesma, porém, é necessário utilizá-lo como recurso didático de modo que o aluno sinta-se ativo e importante no processo de construção do conhecimento, tendo o professor como mediador desse processo.

\section{METODOLOGIA}

Foi proposto um minicurso com foco na formação de professores, utilizando o terrário como tema gerador para Educação Ecológica. Este aconteceu durante a 11ª Semana Nacional de Museus, no Museu de História Natural da Universidade Federal de Lavras.

Inicialmente os prelecionistas apresentaram uma conceituação de Educação Ambiental e Ecológica e a partir disso apresentaram argumentos teóricos que explicavam a utilização de tal atividade para o ensino de Ciências e Biologia. 
Tendo em vista que não seria viável a construção de um terrário durante o minicurso, os prelecionistas optaram por exibir um vídeo de como é feita a montagem. vídeo

(http://pontociencia.org.br/experimentosinterna.php?experimento $=522 \&$ TERRARIO+UM+ECOSSISTEMA+EM+MINIATURA) foi retirado de um portal cuja iniciativa é pioneira na criação de uma comunidade virtual de professores, alunos e entusiastas da ciência.

Após a exibição do vídeo os prelecionistas começaram a abordar quais temas poderiam ser utilizados para ensinar Educação Ecológica a partir da construção, observação e experimentação com elementos constituintes do terrário. A atividade foi filmada para posterior análise das falas dos participantes. Os tópicos explorados no minicurso são apresentados na Tabela 1.

Tabela1: Tópicos explorados durante o minicurso

Materiais empregados na construção do terrário: Solo, garrafa PET ou vidro, plantas e animais.
A partir do solo, sugere-se a construção de questões relacionadas ao surgimento da Terra, explorando as camadas geográficas, além de abordar sua formação e importância na alimentação. Outras questões são 0 uso de agrotóxicos, ocupação desordenada, o desmatamento, etc.

A partir do recipiente - vidro ou garrafa PET -, espera-se elaborar questões que variam desde a produção até 0 descarte destes materiais. Considerando a questão de não reciclagem e a preocupação de descarte incorreto, sugerindo nesse caso a reutilização destes materiais.

Os animais e plantas utilizados possibilitam trazer questionamentos sobre nicho ecológico, habitat, apresentar interações de herbivoria, etc.

Aqui, sugere-se trabalhar as diferenças entre substância e mistura e os processos de separação dessas misturas. É sempre bom lembrar que vários materiais que estão constituindo o terrário como o solo, as pedras, o húmus, o ar, a cola de silicone, o vidro entre outros e os que usamos diariamente, 
Substâncias e misturas

Gases presentes no terrário como plásticos, tintas, refrigerantes, medicamentos, entre outros, são misturas de substâncias.

É possível solicitar aos alunos, que selecionem do terrário um material ou uma substância que eles possam de acordo com sua aparência identificar seus componentes e outra em que isso não seja possível, descrevendo seus aspectos.

Os processos de separação das misturas podem ser abordados com simples experiências complementares aos conteúdos e op professor pode pedir aos alunos que pensem em exemplos de como separar algumas misturas que são encontradas em seu cotidiano.

É possível verificar que os seres vivos não morreram dentro do terrário. As plantas podem crescer e se desenvolver, concluindo que ali estão todos os elementos necessários ao desenvolvimento dos seres vivos, identificando assim, o oxigênio como um desses elementos. Dessa maneira, pode-se trabalhar suas propriedades e sua participação no ciclo energético dos seres vivos, sendo essencial na respiração celular dos organismos aeróbicos.

O ciclo gasoso também é possível de ser trabalhado. A sua sustentabilidade depende também dessa interação, que envolvem etapas biológicas, físicas e químicas alternadamente caracterizando os ciclos biogeoquímicos. Questões como, o efeito estufa e a destruição da camada de ozônio, são temas que devem ser discutidos usando o ciclo do oxigênio como base.

O ciclo do nitrogênio também pode ser trabalhado com o plantio de leguminosas, feijão, por exemplo, a chamada adubação verde, enriquece o solo com compostos nitrogenados, uma vez que nas raízes dessas plantas há nódulos repletos de bactérias fixadoras. 


\section{RESULTADOS E DISCUSSÕES}

Inicialmente os participantes foram questionados sobre o conceito que tinham de educação ambiental, apresentando assim concepções que colocavam o ser humano como parte do ambiente em que vive, mostrando que o papel do mesmo não é apenas uma questão ecológica, mas também de se mostrar atuante na sociedade. Essas concepções trouxeram para discussão o pensamento crítico da EA, comparando com o pensamento conservacionista, que de acordo com Brügger, (1994), preza em suas atividades educacionais uma espécie de "adestramento ambiental", se move pela reprodução do pensamento hegemônico, colocando no indivíduo a ideia de que "o mundo vai mudar se cada um fizer a sua parte". Percebe-se então, a importância de uma EA crítica no cotidiano escolar, já que esta exige a formação de uma "consciência ambiental" e a preparação para o pleno exercício da cidadania, tratando as questões ambientais como sociopolíticas, compreendendo-as para além de suas dimensões biológicas, químicas e físicas (Penteado, 2007).

Essa discussão corrobora com a definição de EA apresentada na Lei No 9.795, de 27 de Abril de 1999:

[...] processos por meio dos quais o indivíduo e a coletividade constroem valores sociais, conhecimentos, habilidades, atitudes e competências voltadas para a conservação do meio ambiente, bem de uso comum do povo, essencial à sadia qualidade de vida e sua sustentabilidade.

Com isso, os participantes demonstraram ser possível abordar um pensamento critico, tendo em vista que diversas situações que ocorrem na natureza podem ser analisadas durante a construção e observação do terrário. Algumas conjunturas estão intimamente ligadas a interesses de uma minoria que por questões econômicas dominam os cenários sociais, sendo assim, espera-se partir de um debate, construir elementos que visem a resignificação de atitudes perante as escolhas no meio ambiente. 
Durante a apresentação dos tópicos, os participantes questionavam e sugeriam temas que consideravam importante para o ensino de ciências e biologia. Ao abordar o primeiro tópico, os participantes sugeriram temas que eram semelhantes aos propostos pelos prelecionistas, e relataram experiências de outros trabalhos que envolviam temas abordados pelo terrário.

Destacamos aqui as falas de alguns participantes:

P1: "Quando a gente fez um trabalho em uma escola os alunos questionavam os desastres causados pelos efeitos da chuva, estando estes relacionados com a profundidade do solo, ocupação, etc. Existe curiosidade dos alunos”.

O participante relata o quanto trabalhos prático-experimentais são importantes no processo de formação dos estudantes e como estes reagem e questionam as situações que Ihes são comuns, oferecendo assim maior significação aos conceitos científicos abordados em sala de aula.

P2: "Eu não imaginei que os próprios constituintes do terrário permitiriam trazer esta discussão".

É importante destacar que os temas a serem abordados com a utilização do terrário não se limitam aos que foram mostrados pelos prelecionistas, ao contrário, se estendem para outros assuntos não trabalhados nesse minicurso. Era importante que os participantes também sugerissem alternativas a serem trabalhadas com esta metodologia.

No terceiro tópico a exibição de algumas imagens relacionadas à poluição urbana, gerada pela emissão de gases poluentes por empresas e veículos automotores possibilitou uma discussão sobre as escolhas individuais do homem diante de uma coletividade. Os participantes então expressaram suas impressões sendo estas apresentadas a seguir:

P3: "Podia usar o terrário como simulador de situação urbana. Uma situação que eu nunca tinha pensado e o minicurso me instigou. Com isso analisar a parte ecológica”.

P4: "Uma coisa que achei muito interessante nesta atividade do terrário é a gama gigantesca de temas que podem ser abordados para ensinar Educação Ambiental. Uma das coisas que eu abordaria seria colocar duas plantas diferentes e trabalhar herbivoria. Outra coisa é colocar fogo e analisar a recuperação do ambiente”. 
As duas falas anteriores demonstram uma visão que está diretamente relacionada à proposta de Jaques et al. (2001) ao problematizar que apesar do terrário ser um modelo experimental que reproduz um ambiente, não existe uma obrigatoriedade na sua construção, de maneira que se torna pertinente inserir, analisar e entender aquilo que julgam necessário em uma determinada situação.

P5: "Quando eu pensava em terrário eu não imaginava essas possibilidades, eu mal sabia o que era terrário".

P6: "Eu ate imaginava ensinar ciências e biologia utilizando o terrário, mas pra Educação Ambiental tinha uma dificuldade de visualizar tantas possibilidades”.

As falas dos participantes P5 e P6 demonstram certa carência na formação de professores. Primeiro pela deficiência no conhecimento do objeto de trabalho em questão e segundo que as informações geralmente são muito limitadas e existe pouco esforço cognitivo num processo de elaboração de uma aula diferenciada.

Essas falas foram retiradas de filmagens feitas durante o minicurso. Os resultados indicaram que a utilização do terrário na formação de professores, se mostrou uma ferramenta com grande potencial como modelo para o processo ensino-aprendizagem em ecologia por favorecer a visualização de seus aspectos conceituais e sociais.

\section{CONCLUSÃO}

No contexto do terrário podemos perceber os ciclos da vida ocorrendo em pequena escala. Através das interações dos componentes bióticos e abióticos dentro do terrário, permite-se a compreensão das relações existentes nos diferentes ecossistemas mundiais. É possível perceber também, com a ajuda de outras ferramentas, a interação entre o homem e o meio ambiente e as alterações a que este ultimo está sujeito. Espera-se que com a utilização do terrário, seja possível desenvolver um pensamento crítico no processo de construção e promover momentos de descontração, relacionando o processo de experimentação com conteúdos presentes nas propostas curriculares e no cotidiano dos 
estudantes, além de atuar como uma prática interdisciplinar. Com isso é possível fornecer subsídios para a instrumentalização do ensino de Ciências e Biologia.

\section{REFERÊNCIAS}

BRASIL. Ciências da natureza, matemática e suas tecnologias / Secretaria de Educação Básica. - Brasília: Ministério da Educação, Secretaria de Educação Básica, 2006. 135 p. (Orientações curriculares para o ensino médio; volume 2)

BOTELHO, L.A. O terrário como instrumento organizador da aprendizagem em Ciências da $8^{a}$ Série ( $9^{\circ}$ Ano). Caderno Pedagógico de Ciências. Secretaria de Estado da Educação - SEED. Programa de Desenvolvimento Educacional - PDE Universidade Tecnológica Federal do Paraná. 2008

BRÜGGER, P. Educação ou Adestramento Ambiental? Florianópolis: Letras Contemporâneas, 1994.

GASPARIN, J.L.; PETENUCCI, M.C. Pedagogia Histórico-crítica: da Teoria à prática no contexto escolar. Campinas- São Paulo: Autores Associados.

KRASILCHICK M. Práticas do ensino de Biologia. São Paulo: EDUSP; 2004.

LOUREIRO, C. F. B.; LAYRARGUES, P. P. Ecologia política, justiça e educação ambiental crítica: perspectivas de aliança contra-hegemônica. Trabalho, Educação e Saúde (Impresso), v. 11, p. 53-71, 2013.

MELO, J.F.R. Desenvolvimento de atividades práticas experimentais de biologia um estudo de caso e uma proposta de material didático de apoio ao professor, Brasília, 2010. 75p 
PARANÁ, Secretaria de Estado da Educação. Diretrizes Curriculares de Ciências para 0

Ensino Fundamental. Curitiba, 2008.

PENTEADO, H. (2007). Meio Ambiente e Formação de Professores. 6 $6^{a}$ edição. São Paulo: Cortez, 2007.

PHILIPPI Jr., A.; PELICIONI, M. C. F. Educação ambiental e sustentabilidade. Barueri, SP: Ed. Manole, 2005.

ROSA, R.T.N. Terrários no ensino de ecossistemas terrestres e teoria ecológica. R.B.E.C.T., vol 2, num 1, jan./abr. 2009

VERONEZ, W.M. et.al. A utilização do terrário para conscientização ambiental de estudantes do ensino básico. R.B.E.C.T., vol 2, núm 3, set/dez. 2009

ÓRGÃOS FINANCIADORES: CAPES/PIBID E FAPEMIG 